\title{
Cuerpos políticos y políticas de la memoria, el caso del memorial a las víctimas en la Universidad Pedagógica Nacional*
}

\author{
Political bodies and politics of memory, the case of the memorial \\ to victims at the Universidad Pedagógica Nacional
}

Corpos políticos e políticos da memória, o caso do memorial às vítimas na Universidad Pedagógica Nacional

\begin{abstract}
Alexander Aldana Bautista**
Universidad Pedagógica Nacional, Bogotá, Colombia

Correo electrónico: aaldanab@pedagógica.edu.co

Revista Corpo-grafías: Estudios críticos de y desde los cuerpos / Volumen 5 - Número 5 / enero - diciembre de 2018 / ISSN impreso 2390-0288, ISSN digital 2590-9398 / Bogotá, D.C., Colombia / pp. 112-124.
\end{abstract}

Fecha de recepción: 23 de mayo de 2017

Fecha de aceptación: 7 de julio de 2017

Doi: https://doi.org/10.14483/25909398.14210

Cómo citar este artículo: Aldana, A. (2018, enero-diciembre). Cuerpos políticos y políticas de la memoria, el caso del memorial a las víctimas en la Universidad Pedagógica Nacional. Revista Corpo-grafías: Estudios críticos de y desde los cuerpos, 5(5), p-p 112-124 / ISSN 2390-0288.

*Artículo de investigación: derivado del proyecto Rostros, Rastros y Trazos, iniciativa de memoria presentada por el autor de este texto en el "Eje de Paz con Justicia y Democracia", en el primer semestre del 2016. La construcción del memorial se inició en junio del 2016 y fue entregado a la comunidad universitaria, el 26 de mayo del 2017. Las otras líneas del proyecto se vienen desarrollando. El Eje de Paz con Justicia y Democracia, es el segundo eje de cuatro, que componen el Plan de Desarrollo Institucional (PDI) 2014-2019, a través del cual la UPN se compromete con una observación continua de las diferentes dimensiones de la violencia, articulando la promoción de los derechos humanos en los ámbitos educativos y "replanteando propuestas pedagógicas e investigativas en el marco de su misión, es decir, apuntando a la formación de formadores para la paz, con capacidad de asumir y formular propuestas en materia de defensa y restitución de derechos (víctimas y sujetos de especial protección constitucional), territorialidad y diálogo de saberes, transformación de conflictos, y políticas educativas con enfoque de derechos humanos" (PDI, 2014, p.89). Este eje cuenta con dos programas y cinco proyectos, uno de ellos es el "laboratorio de iniciativas sobre los núcleos temáticos del eje referidos a paz, convivencia, derechos humanos, ciudadanía, memorias, procesos de paz y posacuerdos". ** Licenciado en Ciencias Sociales y candidato a magister en Educación por la Universidad Pedagógica Nacional. Docente ocasional de la licenciatura en Ciencias Sociales de la Universidad Pedagógica Nacional, Bogotá, Colombia.

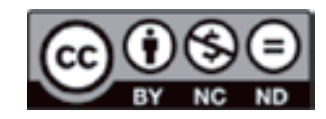


Agradezco a Crisanto Gómez Ráquira, jefe de Bienestar Universitario de la UPN, por haber acompañado esta iniciativa y por su gestión para el desarrollo del memorial. De la misma manera, mi agradecimiento a Daniel Esquivia, con quien comenzamos a hacer posible este proyecto.

\title{
Resumen
}

En este artículo se presenta el proyecto artístico-pedagógico Rostros, rastros y trazos, que se viene desarrollando en la Universidad Pedagógica Nacional. El proyecto es una iniciativa de construcción de memorias en torno a los estudiantes, egresados, docentes y funcionarios que fueron víctimas del conflicto armado en Colombia y que son reconocidas por la Universidad como sujetos políticos que agenciaron, desde diferentes perspectivas, horizontes de futuro posible. Este proyecto hizo parte del laboratorio de iniciativas del Eje de Paz con Justicia y Democracia y se inscribe dentro del actual Plan de Desarrollo Institucional 2014-2019, Una universidad comprometida con la formación de maestros para una Colombia en paz. En este texto se entiende que la construcción visual de las víctimas es un modo de aparición en el que se configuran unos cuerpos políticos que no solo dan cuenta de la ausencia, sino que están articulados a los repertorios ético-políticos en los que tienen lugar las exigencias de verdad y justicia que demandan sus familiares.

Palabras clave: memorial; ausencia; arte; políticas de memoria; cuerpos políticos.

\begin{abstract}
This article presents the artistic-pedagogical project Rostros, rastros y trazos ("faces, traces and lines") which is being developed at Universidad Pedagógica Nacional. The project is an initiative of constructing memories including students, graduates, teachers and employees who were victims of the armed conflict in Colombia and who are recognized by the University as political subjects who, under different perspectives, promoted horizons of a possible future. This project was part of the laboratory of initiatives of the work axis "Peace with Justice and Democracy" and is inscribed in the currently valid Institutional Development Plan 2014-2019 Una universidad comprometida con la formación de maestros para una Colombia en paz (a university committed with the training of teachers for a peaceful Colombia). This text sets out from the idea that the visual construction of victims is a way of apparition where political bodies are presented that not only illustrate absence but are also articulated to the ethic-political repertoires where the relatives' claims for truth and justice have their space.
\end{abstract}

Keywords: memorial; absence; art; politics of memory; political bodies.

\section{Resumo}

Este artigo apresenta o projeto artístico-pedagógico Rostros, rastros y trazos, que está sendo desenvolvido na Universidad Pedagógica Nacional. O projeto é uma iniciativa para construir memórias ao redor estudantes, alunos, professores e funcionários que foram vítimas de conflito armado na Colômbia e que são reconhecidos pela universidade como sujeitos políticos que agenciaron, a partir de diferentes perspectivas, horizontes possível futuro. Este projeto fez parte das iniciativas de laboratório Axis for Peace com a Justiça e Democracia e faz parte do atual Plano de Desenvolvimento Institucional 2014-2019 Uma universidade comprometida com a formação de professores em paz para a Colômbia. Este texto é entendido que a construção visual das vítimas é um modo de aparição em que alguns órgãos políticos que não só perceber a ausência, mas são articuladas aos repertórios éticas e políticas em que ocorrem são definidas a demandas de verdade e justiça exigidas por seus parentes.

Palavras-chave: memorial; ausência; arte; política da memória; corpos políticos. 
"El arte no puede explicar sino puede revelar cosas -por eso el arte es tan importante y necesario aqui" Doris Salcedo

“¿Cómo vivir después del horror? El mal sufrido debe inscribirse en la memoria colectiva, pero para dar una nueva oportunidad al porvenir" Tzvetan Todorov

\section{¿Qué es el proyecto Rostros, rastros y trazos?}

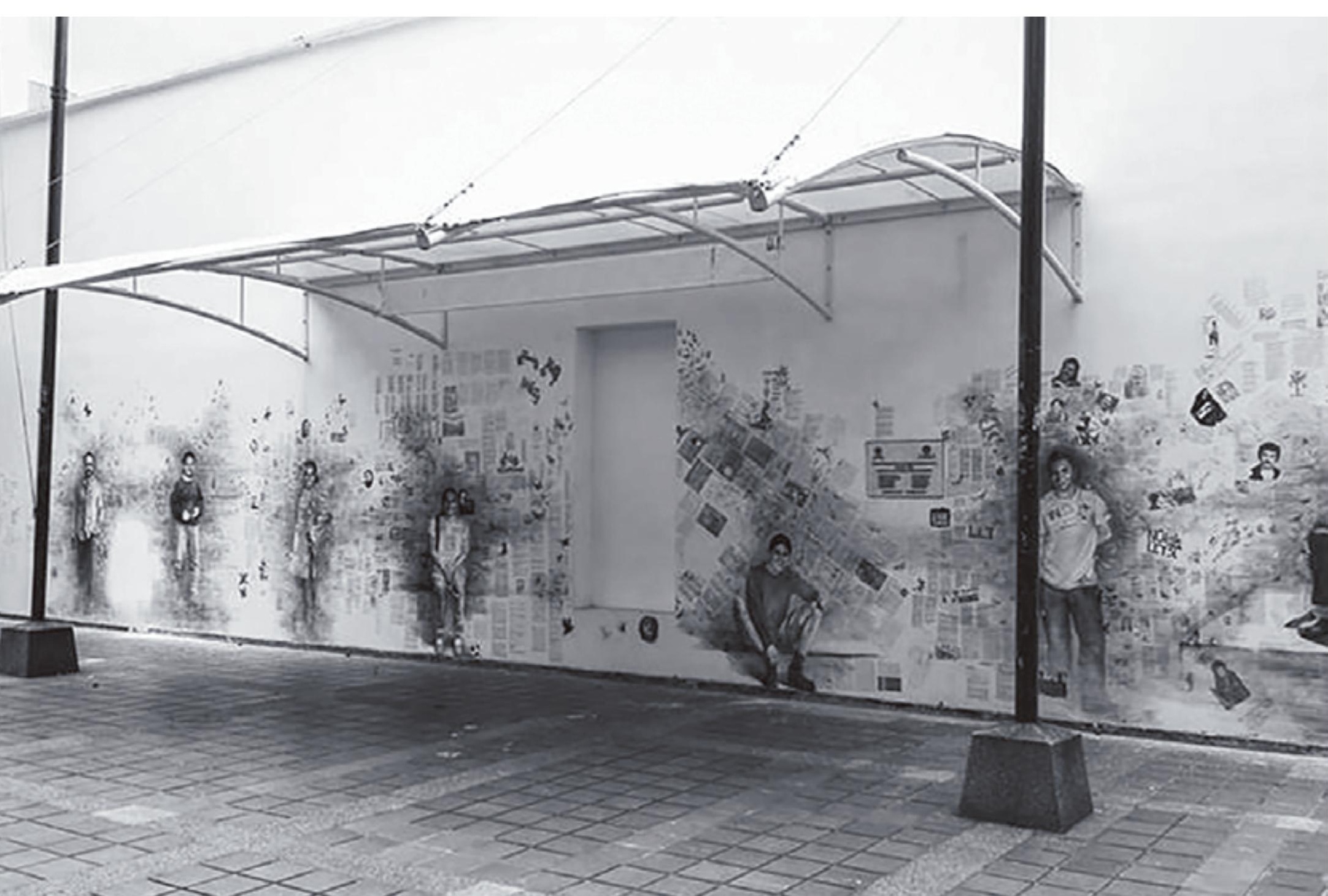


En una pared de 20 metros de longitud, en el patio del edificio P, donde se encuentra la rectoría, se desarrolló la primera línea del proyecto memorialistico Rostros, rastros y trazos.

Este proyecto, se inscribe dentro del actual Plan Desarrollo Institucional -PDI- Una universidad comprometida con la formación de maestros para una Colombia en paz, en el programa 2, del eje 2 Construcción de paz con justicia y democracia. Esta iniciativa participativa de construcción de memorias es una forma de dignificar a las víctimas, reconociéndolas como sujetos políticos que desde diferentes trayectos vitales aportaron a la construcción de una comunidad académica autónoma y crítica. Como opción ética, política y estética, este proyecto se orienta a construir horizontes de futuro diferentes, para hacer del pasado doloroso una experiencia «operante y transmisible» que posibilite, en la comunidad educativa, la promoción de valores democráticos y la defensa de los derechos humanos.

En este proyecto memorialistico, se pueden ubicar cinco líneas de acción: en la primera, se busca trazar el rostro de las víctimas del conflicto armado en la UPN a través de su dibujo a escala real ${ }^{1}$, en la Plazoleta de la memoria, patio del edificio $\mathrm{P}^{2}$ (Imagen1,2); en una segunda línea, el objetivo es abrir espacios para la conmemoración, los rituales de memoria y los actos simbólicos que posibiliten el encuentro de la comunidad universitaria a partir del recuerdo; en una tercera línea, se pretende diseñar e implementar estrategias didácticas para trabajar en torno al memorial, con niños, niñas y adolescentes; en cuarto lugar se busca construir un archivo de la memoria, documentando cada caso y por último, se pretende hacer seguimiento legal a cada uno de los casos, reclamando verdad y justicia.

1 El memorial está compuesto por el dibujo de nueve víctimas: Carlos Alberto Pedraza Salcedo, licenciado en Ciencias Sociales (1981-2015); Daniel Andrés Garzón Riveros, estudiante de la Licenciatura en Ciencias Sociales (1989-2012); Oscar Danilo Arcos, estudiante de la Licenciatura en Ciencias Sociales (1989-2012); Lizaida María Ruiz Borja, licenciada en Educación Básica Español-Inglés (1989-2012); Golson Granados, estudiante de la Licenciatura en Educación Física (1976-2001); Miguel Ángel Quiroga, licenciado en Ciencias Sociales (1971-1998); Darío Betancourt Echeverry, profesor del Departamento de Ciencias Sociales (1952-1999); Eduardo Loffsner Torres, trabajador y dirigente sindical (1955-1986) y, Cristina del Pilar Guarín, licenciada en Ciencias Sociales (1958-1985).

2 El edificio, se encuentra ubicado sobre la calle 73 en la sede central de la UPN, en la calle 72 con carrera 11 en Bogotá, Colombia.

Imagen 2. Boceto inicial del memorial, elaborado por

el artista Daniel Esquivia Zapata en junio del 2016.
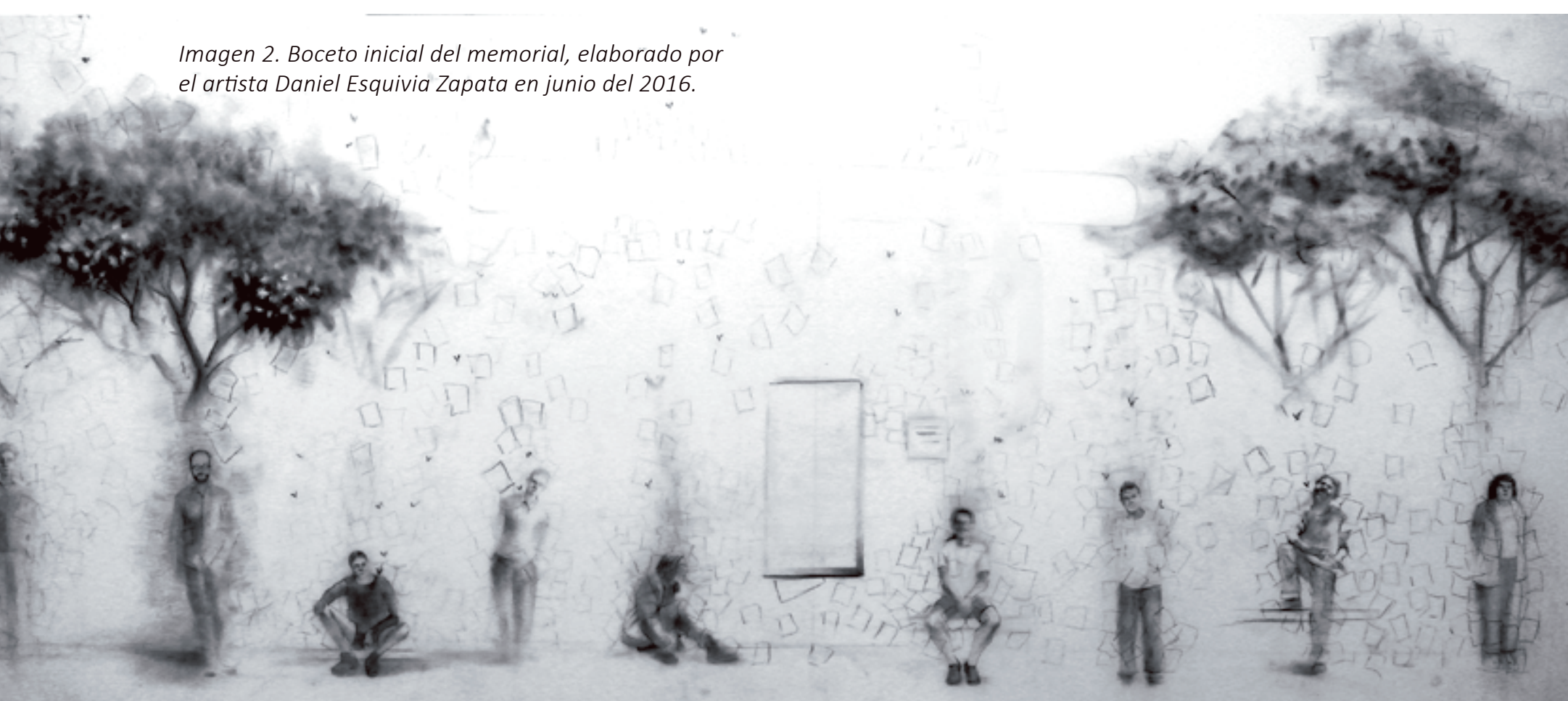
Como una forma de reparación simbólica a las familias que han sido víctimas del conflicto armado en Colombia y en la Universidad Pedagógica Nacional, este proyecto se articula al propósito de que "la Universidad ingresará en el plano nacional del reconocimiento a las víctimas del conflicto, como escenario para la construcción de paz con apelación a la memoria" (PDI 2014-2019). Se trata en efecto, de hacer memoria con el firme propósito de reclamar verdad y justicia en cada uno de los casos en que fue vulnerado el derecho a la vida y a la integridad física, psicológica y moral de algún miembro de la comunidad universitaria.

Así pues, la UPN viene desarrollando acciones y propuestas tendientes a transmitir a las nuevas generaciones de maestros y maestras, un pasado no cristalizado ni momificado en efemérides, sino que la misma Universidad se ha constituido en un escenario de luchas por la memoria, evitando cerrar el pasado en una sola versión, que pierda su articulación con el presente e imposibilite proyectar otros futuros. El "deber de memoria", es pues, una acción colectiva que busca dignificar a las víctimas, por lo que esta iniciativa ha contado con la participación de los familiares y amigos de nueve de las víctimas, ellas y ellos han elaborado las semblanzas de sus seres queridos, han estado vinculados a diferentes encuentros de reflexión y, han aportado y transferido los textos que aparecen rodeando los cuerpos que aparecen en este memorial.

Alrededor de cada uno de los dibujos que Daniel Esquiva Zapata ${ }^{3}$ elaboró, se transfirieron textos e imágenes alusivas a cada víctima (Imagen 3), de tal manera que los textos entraran a dialogar con la imagen, se trata de la misma técnica que el artista utilizó en el trabajo Dos formas de recordar y que se caracteriza por "formatos irregulares en los cuales las capas de papel se cruzan con capas de texto, dejando en evidencia esas otras historias que graban los cuerpos, que dibujan las memorias y que se agotan tras capas de olvido" (Aldana, 2016, p.29).

\begin{abstract}
3 Daniel Esquivia Zapata es el artista invitado por la UPN para desarrollar la primera línea de acción de este proyecto. "Nació en San Jacinto, en el departamento de Bolívar, en 1987. A muy temprana edad tuvo que dejar su lugar de origen con su familia, desplazados por la violencia paramilitar. Después de pasar por varias ciudades del país, la familia de Daniel se radicó en la ciudad de Bogotá donde fueron acogidos por la comunidad menonita. En el año 2004, Daniel ganó una beca para dar inicio a sus estudios profesionales en arte en el Benedict College de Columbia, (Carolina del Sur) una universidad históricamente dedicada a educar a la comunidad negra. En 2008, al terminar sus estudios, se graduó con honores summa cum laude y recibió una beca para iniciar un programa de maestría en dibujo en The New York Academy of Arts. Con la ayuda de COLFUTURO, Daniel terminó sus estudios de maestría en el año 2011, obteniendo de nuevo un grado honorífico, además del Sant Barths Residency y un premio a la excelencia de parte de la universidad" (COLFUTURO, 2013, en línea).

4 Este trabajo artístico, se expuso entre el 14 de septiembre y el 10 de octubre de 2015, en el Centro Cultural Gabriel Betancourt Mejía de la Universidad Pedagógica Nacional. La exposición no solo muestra dos técnicas diferentes, el dibujo y la litografía, a través de las cuales el artista pone a circular sus recuerdos y sus sentimientos frente a un hecho violento y traza la imagen de sus parientes y amigos que cuentan historias, que guardan secretos, que mantienen en sus manos el pasado sino, que la exposición se constituye, en una posibilidad para hacer de estas narrativas artísticas un medio para hacer decible, para comunicar el pasado.
\end{abstract}

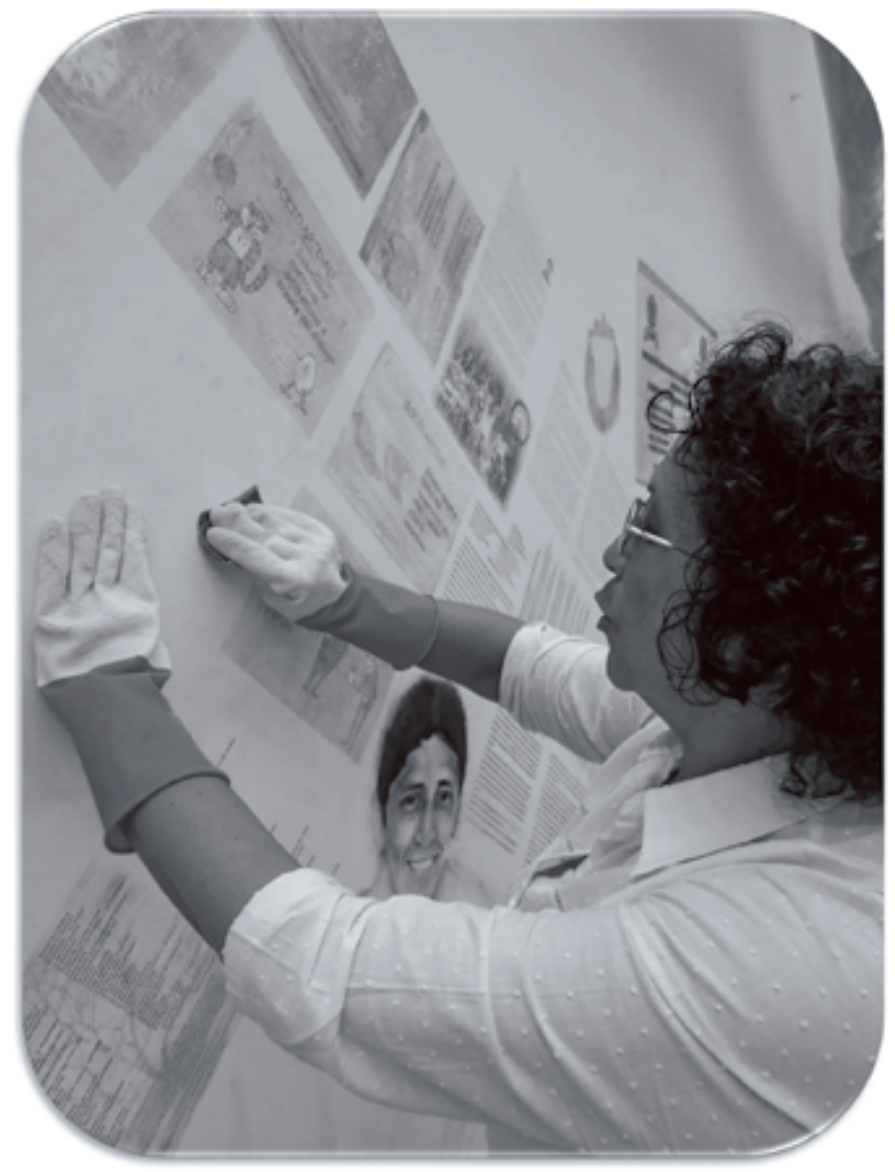

Imagen 3. Familiares y amigos de las víctimas transfiriendo algunos textos en los que se hace referencia a su ser querido o que son de la autoría de él o ella. En la foto se ve a Noemi, madre de Golson Granos, lijando la superficie de la pared para transferir los textos. 
Cabe señalar que Daniel Esquivia, realizó un trabajo etnográfico con seis de las nueve familias, para reconstruir los rasgos físicos de sus seres queridos. Este ejercicio posibilitó tejer confianzas, dialogar en torno a los gustos, apuestas políticas y la cotidianidad de las víctimas e intercambiar fotos para construir los bocetos de la propuesta artística (Imagen 4).

Como parte de este deber de memoria y como una acción artísticapedagógica que busca contribuir a la elaboración del trauma social causado por el conflicto armado, la UPN desde diferentes ámbitos, estrategias y acciones busca contribuir a la construcción de una sociedad capaz de resolver de manera pacífica sus conflictos, una sociedad en la cual la educación se constituya en la principal garantía de no repetición.

Representar visualmente la ausencia provocada por la violencia política, plantea algunos retos. De un lado, se hace memoria en medio del conflicto armado y de las disputas por los sentidos de lo ocurrido. Del otro lado, esta construcción de memorias se realiza desde el arte, entonces la encrucijada es latente: ¿cómo representar lo irrepresentable?, ¿de qué maneras nombrar aquellas experiencias límite? Siguiendo a Battiti (2010) "pareciera entonces que, ante el límite, el arte sufre una suerte de insuficiencia de representación pero, paradójicamente, logra fundarse en esa misma imposibilidad" (p.73). Desde el arte se busca construir memorias y restablecer la trama cultural rasgada por la violencia en Colombia, así, este memorial busca dejar huella, inscribir en el presente el pasado, alimentando la identidad institucional de la Universidad.

El memorial a las víctimas de la UPN no se puede entender tan solo como un mural, se trata de un lugar de recuerdo y homenaje a los asesinados y desaparecidos por una lógica de poder que busca "Matar, Rematar y Cotramatar", utilizando la expresión del texto de María Victoria Uribe (1978). Este espacio público que hace parte de la UPN y de la ciudad, propone una experiencia con el pasado que no está en los dibujos, en los trazos, sino en lo que el espectador siente al recorrer los 20 metros de largo de la pared de la plazoleta de la memoria y observar cada cuerpo en medio de textos e imágenes que le otorgan identidad. De esta manera, se

Imagen 4. Boceto de la imagen de Miguel

Ángel Quiroga, elaborado por Daniel Esquivia en junio del 2016. 
puede dimensionar la inmensa tragedia de la perdida y de la ausencia cuyo sentido no aparece unificado y cerrado. Los significados que emergen de la experiencia de observar estos dibujos se expresan en las maneras como las y los estudiantes de la UPN interactúan con estos cuerpos y en los modos como se ritualizan prácticas de memoria en torno a él.

\section{"Aquí estamos tejiendo memorias"5}

Este proyecto memorialistico que se adelanta en la UPN, se pude inscribir dentro "la obsesión memorial", que autoras como Leonor Arrfuch (2008) han analizado desde una peculiar experiencia estética, en la que se transita de la complacencia receptiva a la primacía de espectador, "que es a su vez una solicitación dialógica al esfuerzo de la interpretación, a la vibración de la experiencia, a la invención del efecto y no a una mera complacencia receptiva" (Arfuch 2008, p.115). Así, esta propuesta artística desarrollada por Daniel Esquivia, interpela al observador al hacer ver a dos mujeres y siete hombres en una naturalidad que raya con lo real, que quiebra la uniformidad del espacio, que trae al presente lo ausente y que posibilita cuestionar los regímenes visuales a través de los cuales se muestran los pasados recientes y se construyen formas hegemónicas de representación del dolor. Pero ¿qué tipo de experiencia se busca construir con esta propuesta memorialistica? Lejos de tratarse de un proyecto de institucionalización de la memoria que demanda la construcción de un tipo de recuerdo como el correcto y el que debe ser compartido, esta iniciativa se planteó como finalidad, entrar a dialogar con otros soportes de memoria que hacen parte del inventario simbólico de la UPN, iniciativas que desde los grupos de estudiantes han buscado conservar la memoria del profesor Darío Betancourt, de Carlos Pedraza o de Lizaida, Oscar y Daniel, marcando el espacio universitario con placas, murales y "pintas" que mantienen para las nuevas generaciones de maestros, un pasado presente.

Este memorial a las víctimas es una forma de construcción de "una memoria pública" a través de una marca en el espacio universitario que, siguiendo a Messina (2008), hace referencia "a las inscripciones de sentido producidas por sujetos sociales sobre aquellos espacios materiales que resultan significativos para ellos" (p.136). Esta pared del edificio P, condensa para los familiares de las víctimas y para parte de la comunidad universitaria, sentidos sobre el pasado, que entraron a circular a través de los dibujos elaborados por Daniel en el espacio académico universitario y que se articulan a identidades políticas y sociales. Este proceso de marcación del espacio no estuvo ajeno a debates, controversias y pugnas entre diferentes actores de la Universidad, que en la construcción de los perfiles dejaron en evidencia que las formas del recuerdo están asociadas al tiempo que compartieron con las víctimas y a aquellas experiencias y proyectos que adelantaron de manera mancomunada. Preguntar por los gestos cotidianos, la forma de caminar, vestir, comer o hablar, de alguna de las víctimas fue evocar experiencias, revivir sentimientos y narrar desde el presente una forma de ser y estar de aquellos y aquellas que habían permanecido invisibilizados para otros gobiernos universitarios y sobre los cuales se establecieron olvidos institucionalizados, como en el caso de María Cristina Guarín a la que se le negó el acta de grado pues fue borrada de los libros de registro de los estudiantes de la Universidad.

Esta forma de marcar el espacio universitario es una forma de intervención del espacio público, lo que significó sacar del espacio doméstico, de la intimidad, el recuerdo y hacerlo visible, compartirlo, ponerlo a circular para hacer de las imágenes del pasado, de la estética del recuerdo posibilidades para reflexionar y aprender. En este sentido, siguiendo a Nelly Richard (2013):

5 Esta fue la frase que se ubicó sobre uno de los plásticos que cubrió el muro de 20 metros en el cual se desarrolló la propuesta artística por parte de Daniel Esquivia. La metáfora del tejer remite a entrelazar hilos o fibras hasta alcanzar un tejido, así, en las memorias se entrelazan diferentes perspectivas y significados del pasado que hacen que este sea un espacio de conflictos por su apropiación y reproducción. 
El arte debe articular políticamente y estéticamente la mirada para que la relación con las imágenes del pasado sea intensiva y problematizadora a la vez, descifradora y enjuiciadora, ya que las imágenes deben ser no sólo "vistas" (consumidas por la vista) sino, según nos dice S. Sontag, "examinadas" por la conciencia crítica (p.88).

Arte y memoria se articulan para mantener viva la memoria, para abrir el pasado a una pluralidad de sentidos. En este caso, el artista logra que el desprevenido transeúnte se detenga a mirar, y se acerque a tratar de leer los textos que componen la obra, el poder de la obra de arte es entonces el de deshabituar la mirada, el de cuestionar la cotidianidad, el de comunicar el pasado en el presente, el de abrir interrogantes -nunca dar respuestas ni impartir verdades sobre lo que sucedió- La criticidad de ese arte de la memoria, sostiene Richard, "se debe a la exacta tensión contenidos de representación (el "qué" del pasado) y estrategias de lenguaje (el "cómo" del recordar) para involucrar a lo trascurrido en una nueva narrativa recreadora de experiencia" (2013, p.89).

"Hacer memoria", es un fenómeno cultural y un proceso de aprendizaje a través del cual los sujetos, en un grupo social le otorgan sentido al pasado y hacen uso de él, de acuerdo con un sistema de valores que le es propio. La memoria no se puede

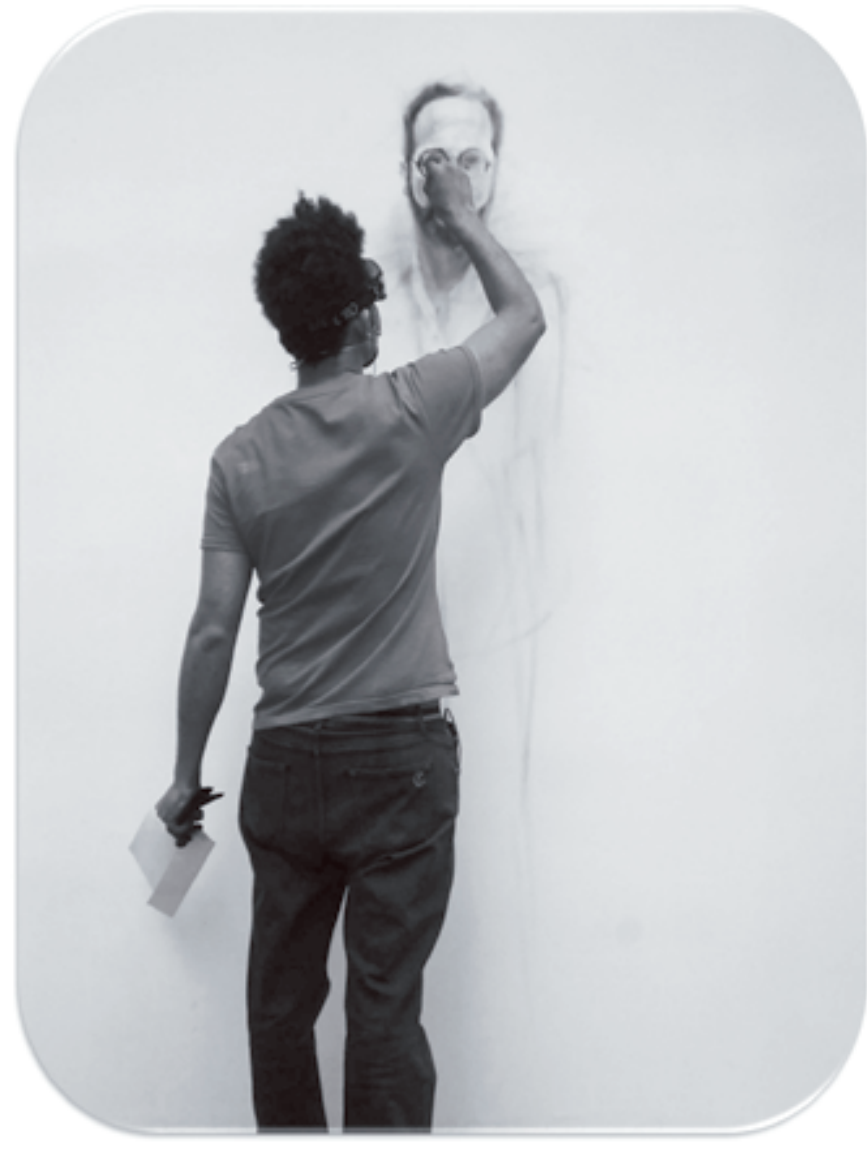

Imagen 5. Daniel Esquivia Zapata realizando los trazos del rostro del profesor Darío Betancourt Echeverry.

entender solo como aquello que evocamos sino como la tensión entre recuerdo y olvido, es por esto, que la memoria no se opone al olvido, sino que en ella emergen tensiones, luchas y conflictos por el pasado que van a ser de gran importancia en la configuración de las identidades colectivas.

La memoria es entonces plural y multiforme, es un proceso abierto de reinterpretaciones del pasado. Volver al pasado es una experiencia política y ética que se realiza desde el presente mediante actos de rememorar/olvidar: el presente contiene la experiencia pasada y las experiencias futuras.

Ahora bien, las dinámicas propias de la violencia política en Colombia, que se ha extendido por más de cinco décadas en el marco de un sistema democrático precario, han ocasionado entre 1958 y 2012 la muerte de 220.000 personas, , que han sido víctimas por la acción de diferentes actores armados, en distintas modalidades violentas; según el Grupo de Memoria Histórica (2013). Este conflicto, que no tiene una modalidad distintiva, sino en el que todos los actores armados han conjugado diferentes modalidades de violencia, ellos hicieron de la población civil la principal víctima del conflicto. 
Pero no todos los grupos y organizaciones armadas practicaron con la misma intensidad y con igual grado de sevicia las modalidades de violencia, aunque todos fundaron en ella sus estrategias. La evidencia empírica que arrojan los casos emblemáticos y la información cuantitativa registrada en diferentes fuentes refleja que, en términos de repertorios de violencia, los paramilitares ejecutaron en mayor medida masacres, asesinatos selectivos y desapariciones forzadas, e hicieron de la sevicia una práctica recurrente con el objeto de incrementar su potencial de intimidación. Las guerrillas, por su parte han recurrido primordialmente a los secuestros, los asesinatos selectivos, y los atentados terroristas, además del reclutamiento forzado y el ataque a bienes civiles. Con respecto a la violencia ilegal de miembros de la Fuerza Pública, se ha podido establecer con base en testimonios y en sentencias judiciales el empleo de modalidades como las detenciones arbitrarias, las torturas, los asesinatos selectivos y las desapariciones forzadas" (Grupo de Memoria Histórica, 2013, p.20).

En este orden de ideas, la transición hacia la paz y hacia una sociedad democrática y respetuosa de las diferencias, requiere necesariamente de procesos que permitan el esclarecimiento de los hechos violentos, además de que el Estado debe garantizar los derechos de las víctimas a la verdad, la justicia, la reparación y las garantías de no repetición. Así, el derecho a la verdad implica el reconocimiento social de lo que ha pasado y la preservación de la memoria que previene "contra el surgimiento de tesis revisionistas o negacionistas sobre lo ocurrido en el pasado violento" (GMH, 2013, p. 398). El deber de memoria no solo se puede expresar en las responsabilidades del Estado para contribuir a la realización del derecho a la verdad sino que invita a la sociedad colombiana en general a crear mecanismos que permitan visibilizar los hechos violentos, preservar los archivos de los organismos de seguridad del Estado con el propósito de explicar la participación de agentes estatales en acciones en las que se vulneraron los Derechos Humanos y, desarrollar propuestas pedagógicas a través de las cuales las nuevas generaciones y los diferentes actores sociales reconozcan las causas y los actores del conflicto armado así como las luchas y los proyectos de sociedad que las víctimas agenciaban desde diferentes organizaciones y sectores sociales.

Entendido así, el deber de memoria como acción colectiva busca dignificar a las víctimas con la participación activa de sus familiares y de los grupos sociales a los cuales estaban vinculados.

Como parte de este deber de memoria y como una acción artística-pedagógica que busca contribuir a la elaboración del trauma social causado por el conflicto armado, la Universidad Pedagógica Nacional desde diferentes ámbitos, estrategias y acciones busca contribuir a la construcción de una sociedad capaz de resolver de manera pacífica sus conflictos, una sociedad en la cual la educación se constituya en la principal garantía de no repetición. Una de esas estrategias está dirigida a la construcción de este memorial que incluye el cuerpo de las víctimas y sus entramados simbólicos. Son trazos que no buscan revictimizar como tampoco decir la verdad sobre los hechos violentos en los que cada una de ellas fue asesinada o desaparecida, el memorial a las víctimas de la UPN aspira a ser un lugar de memoria, un sitio de interés nacional donde sea posible "recuperar la dimensión existencial de estas ausencias", haciendo visibles sus proyectos de vida y sus ideales para lograr, a partir de la educación y del arte, mantener viva la memoria de los profesores, estudiantes, funcionarios y egresados que fueron víctimas del conflicto armado. 


\section{(Des)dibujando cuerpos}

Nunca como hoy, en Colombia, el tema de las memorias del conflicto había sido objeto de reflexión académica, de interés público y de acciones en el espacio: desde instalaciones hasta exposiciones fotográficas, pasando por performances, obras de teatro y producciones cinematográficas, que dan cuenta de una efervescencia de la memoria que se expresa en los usos públicos del pasado y en políticas que configuran sentidos en torno a las experiencias que produce vivir en medio de un conflicto armado. La construcción de este memorial en que aparecen los dibujos de las víctimas de la Universidad Pedagógica Nacional, desborda la lógica de "recordar para no olvidar", pues si bien la memoria se funda en la tensión entre recuerdo y olvido, la reflexión que proponemos gira en torno a estas cuestiones: ¿quiénes recuerdan a las víctimas?, ¿desde qué marcos de sentidos y apuestas políticas son recordadas?, ¿qué hacen ver estos dibujos de las víctimas?

Se puede decir entonces, que este memorial descansa sobre el horror de la violencia política, siguiendo a Benjamín (1982) los bienes culturales "tienen todos y cada uno un origen que no podrá considerar sin horror. Deben su existencia no solo al esfuerzo de los grandes genios que los han creado, sino también a la servidumbre anónima de sus contemporáneos. Jamás se da un documento de cultura sin que lo sea a la vez de la barbarie" (p. 82). Así, ha sido la violencia y sus estragos un elemento primordial en los procesos de creación artística en Colombia y en ellos aparece una y otra vez los cuerpos que deja la guerra: hombres y mujeres con sus enceres al hombro huyendo del fuego cruzado entre los actores armados; cuerpos despresados bajando por las aguas de un río; cuerpos torturados; cuerpos mutilados; cuerpos privados de su libertad y, la sombra del cuerpo: el vacío que dejan aquellos cuerpos desaparecidos.

Lo anterior permite evidenciar la forma como sobre los cuerpos ha operado una "anatomopolítica de la guerra", la cual busca disciplinar a la sociedad a través de un conjunto de técnicas que producen sufrimiento en los individuos y conducen a la muerte. El cuerpo del individuo sirve aquí para generar temor en una comunidad, para ejercer dominio sobre otros cuerpos y para controlar el territorio, así, el ejercicio de la guerra sobre el cuerpo de un individuo hace que funcione como una pieza que se engrana a un conjunto mucho más amplio: un régimen de verdad en el cual la vigilancia y el control de los cuerpos produce obediencia. La anatomopolítica de la guerra tiene como propósito señalar los cuerpos, nombrarlos, catalogarlos y clasificarlos para silenciarlos, para hacerlos invisibles.

El cuerpo que produce esta anatomopolítica es un cuerpo fabricado a través de artefactos de guerra, por lo tanto, el que opera es un poder creativo que su fin último no es la muerte sino el sufrimiento, el dolor hasta llegar a borrar cualquier vestigio de humanidad. En tanto no existe poder sin resistencia, dibujar los cuerpos de las víctimas es un acto de resistencia que se sitúa en el límite de lo inenarrable, es un acto (re)creativo a través del cual se hace visible lo ausente. Es esta forma de resistencia la que posibilitó un espacio reflexivo y expresivo en el cual los cuerpos de los familiares y amigos de las víctimas conformaron un cuerpo colectivo que se articuló a través de la práctica artística que propuso el artista invitado para la realización del memorial.

La construcción del memorial a las víctimas de la Universidad Pedagógica fue un acto re-creativo desde y con el cuerpo. Cuerpos que abandonaron la intimidad del espacio doméstico, que dejaron de estar en las fotografías familiares para aparecer en el espacio público. Esta forma de aparición obedece a una política de los cuerpos que toma distancia de aquellos modos generalizados de representar la muerte desde el horror, desde la transgresión violenta de la mirada, que se queda con el cuerpo desmembrado, con el baño de sangre, con el espectáculo de la guerra. Según Restrepo (2006), 
La violencia se ensaña con los cuerpos. Cuerpos heridos, abiertos, desmembrados, expuestos en una disolución violenta de las formas, provocan la caída en el abismo del horror. Horror que también fascina y crea adeptos. Horror que ejerce su poder político rompiendo violentamente el sentido, sembrando la incredulidad y el miedo, diseminando salvajemente su mensaje didáctico. Teatro del horror para que el público no olvide. Ritual cuyo proceso o resultado final (aún después de la muerte) tiene que saltar a la vista: Texto, Teatro y Exposición (p. 20).

Así, se trató de desdibujar para dibujar de otra manera. Cuerpos dibujados con lápices grasos que se vuelven superficie de inscripción de sentidos, de recuerdos y olvidos que se tejen en el acto de la memoria. Entonces opera un cambio de mirada: si bien el contacto con los cuerpos de las victimas de la violencia política se da a través de la imagen fotográfica, este memorial nos hace ver cuerpos en la cotidianidad, cuerpos dibujados, hechos a mano, rodeados de textos e imágenes que configuran su identidad política, su forma de ser y de estar en el mundo.

Encontrar las líneas, los trazos para configurar una apariencia, para hacer que los cuerpos se vuelvan legibles, esa fue la tarea de Daniel Esquivia Zapata, rehacer una identidad violentamente vulnerada por la anatomopolítica de la guerra, identidades presas del olvido y del silencio impuesto. Es por esto por lo que estos nueve cuerpos dibujados, siguiendo a Restrepo (2006) son "el espacio gramatical de lo visible y lo legible" (p. 21), cuerpos gramaticales que hablan, que se manifiestan, que tienen derecho a aparecer.

\section{A modo de cierre provisional}

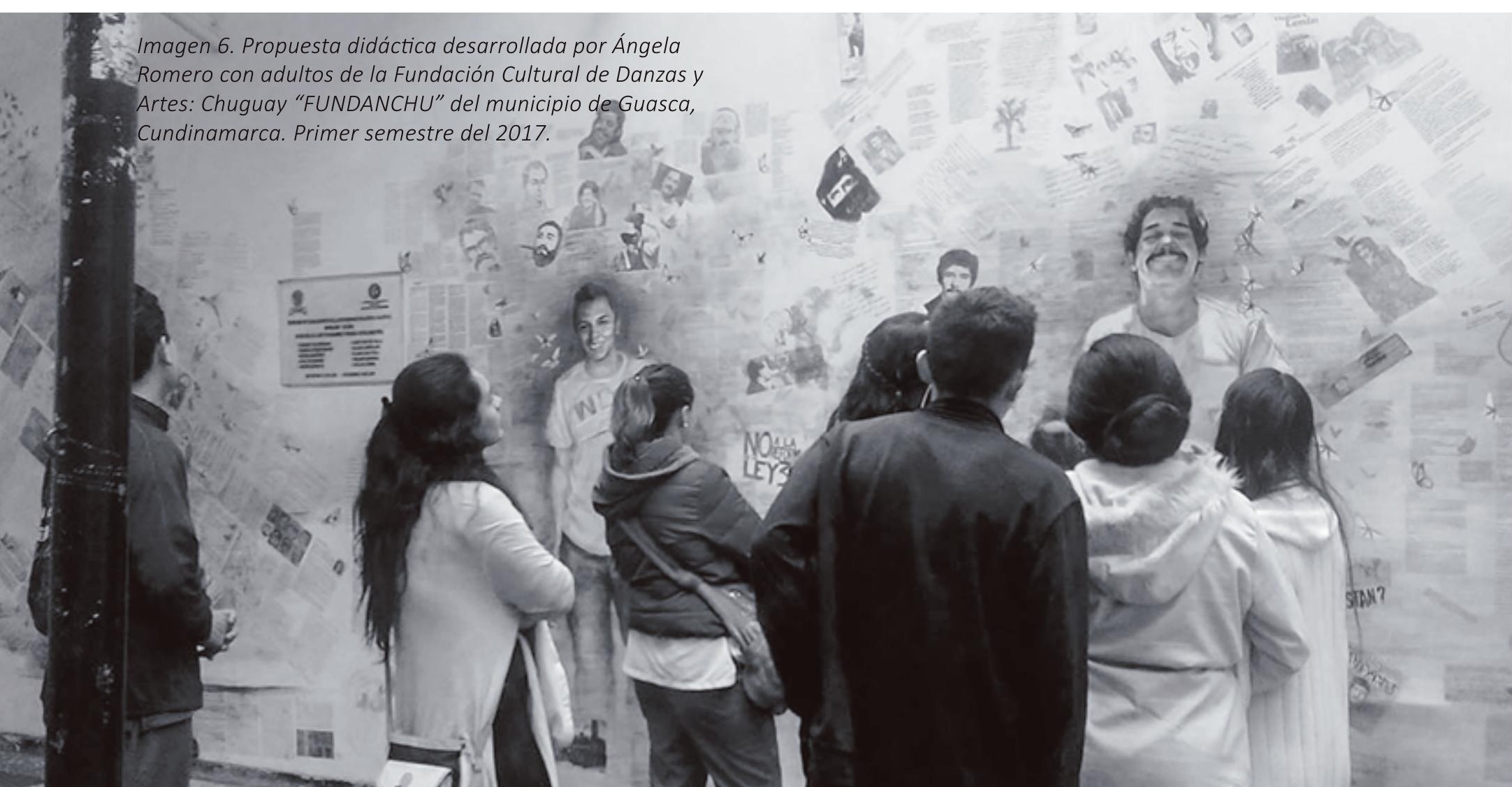




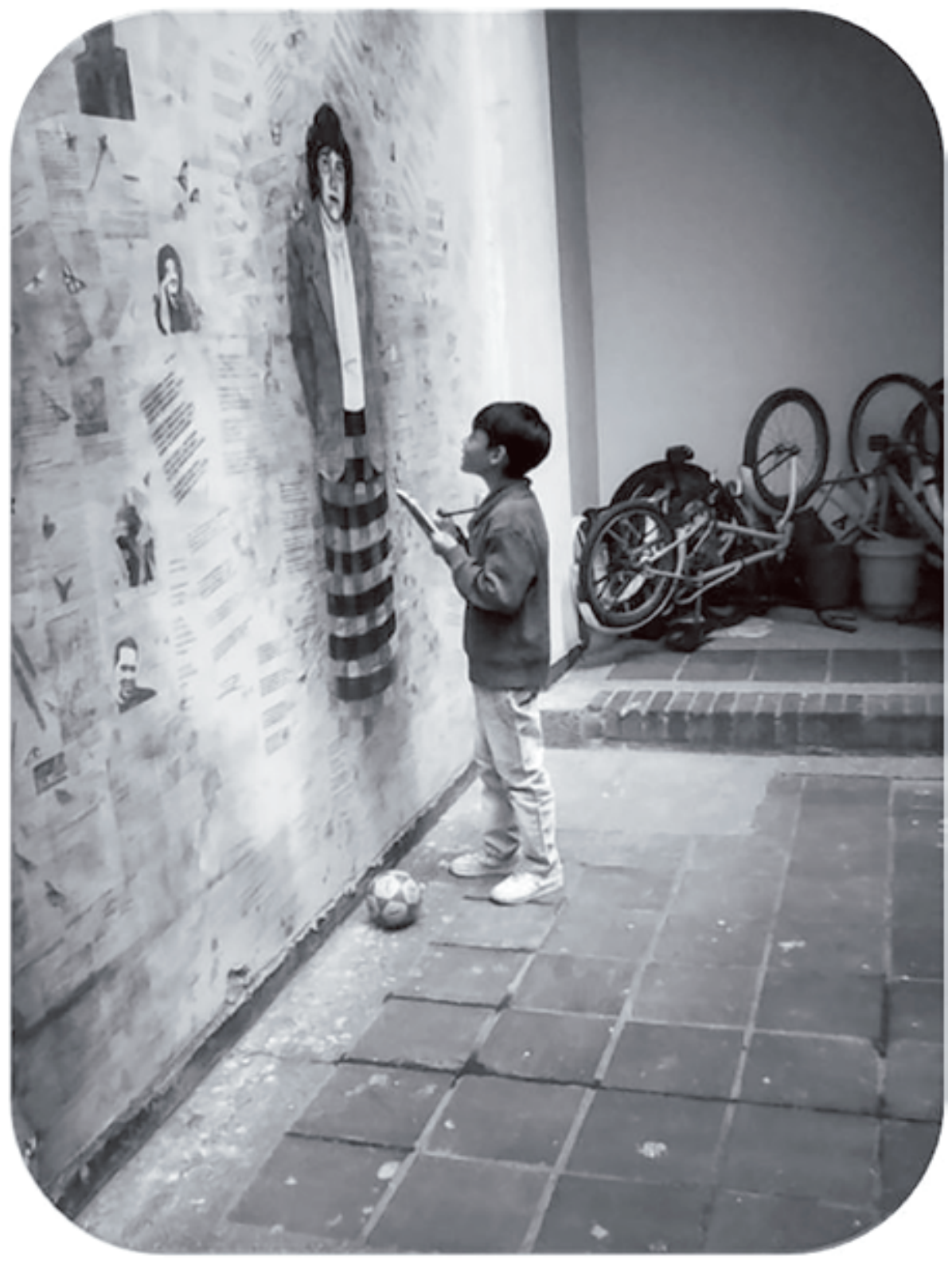

Este proyecto memorialistico se articuló al seminario electivo, Pedagogías de la memoria: arte y construcción de paz, ofertado desde la Licenciatura en Psicología y Pedagogía para el primer semestre de 2016, por lo que se trata no solo de una propuesta estética a través de la cual se busca grabar el rostro de cada una de las víctimas, ya que, este seminario se convirtió en el espacio de discusión y reflexión frente al papel del arte en la construcción de memorias sociales. Así las cosas, se busca estimular el debate entre la comunidad universitaria, acerca de las formas que adquiere el recuerdo y la articulación de estas "manifestaciones artísticas y estéticas" con políticas de la memoria y luchas por la defensa de los Derechos Humanos en el ámbito institucional y nacional.

Se trata, siguiendo a Jelin y Longoni (2005) de "mirar cómo el/la autor/a o artista contribuye a crear sentidos del pasado, siempre en lucha con otros sentidos existentes en el campo en que se mueve, es decir, de qué modo los artefactos culturales intervienen en las pugnas en torno a la memoria". Entonces, ante un evidente uso y abuso de la memoria en una sociedad en transición como la colombiana, ¿cómo y para qué generar propuestas críticas de producción cultural sobre el conflicto armado?, ¿de qué maneras estas manifestaciones artísticas y estéticas posibilitan espacios educativos y formativos?

Imagen 7. Propuesta didáctica llevada a cabo por Natalia Suárez con niños y niñas, en mayo del 2017. 
Para finalizar, cabe señalar que después de que fue entregado el memorial a la comunidad educativa, desde el seminario de Memoria, Territorio y construcción de identidad ${ }^{6}$, se ha alentado a los estudiantes a que diseñen e implemente diferentes estrategias didácticas para trabajar con el memorial la construcción de memorias sociales en torno al conflicto armado y el movimiento estudiantil, como resultado de este ejercicio se desarrollaron cinco propuestas durante el primer semestre de 2017 (Imágenes 6 y 7). Así mismo, se han llevado a cabo dos rituales de la memoria: el primero en septiembre de 2016, recordando a Miguel Ángel Quiroga y el otro en diciembre del mimo año, fecha en la que se conmemora el natalicio de Carlos Pedraza.

6 Este seminario es de carácter obligatorio en la Licenciatura de Ciencias Sociales y es visto en sexto semestre.

\section{Referencias}

Aldana, A. (2016). "Melquiades y los desafíos de la memoria”, en Pierre Valls (director del proyecto). Fe de erratas: arte y política. Ciudad de México: Ediciones Colaterales..

Arfuch, L. (2008). "Arte, memoria, experiencia: políticas de lo real”, en Leonor Arfuch y Gisela Catanzaro, (Comp.). Pretérito imperfecto. Lecturas críticas del acontecer. Buenos Aires: Prometeo libros.

Battiti, F. (2010). E"I arte ante las paradojas de la representación", en Monumento a las víctimas del terrorismo de Estado. Parque de la memoria. Buenos Aires: Consejo de Gestión Parque de la Memoria. Gobierno de la Ciudad de Buenos Aires.

Benjamin, W. (1982). "Tesis de filosofía de la historia”, en Discursos interrumpidos I. Madrid: Taurus.

Colfuturo, (2013). Dos formas de recordar de Daniel Esquivia se expuso en Bogotá. En línea. [consultado 22 de septiembre de 2017]. Disponible en https://www.colfuturo.org/dos-formas-de-recordar-de-daniel-esquivia-se-expuso-en-bogota

Jelin, E. (2012). Los trabajos de la memoria. 2a. ed. Lima: Instituto de Estudios Peruanos -IEP-

Messina, L. (2008-2010). "La construcción de un lugar de memoria: el caso del ex centro clandestino de detención "olimpo"”. Cuadernos del Instituto Nacional de Antropología y Pensamiento Latinoamericano, 22., pp. 135-144.

Restrepo, J. A. (2006). Cuerpo gramatical. Cuerpo, arte y violencia. Bogotá: Ediciones Uniandes. Universidad de los Andes. Facultad de Artes y Humanidades.

Richard, N. (2013). Fracturas de la memoria: arte y pensamiento crítico. Buenos Aires: Siglo XXI Editores. (1ạ reimpresión). 